\title{
Model Percakapan untuk Menanamkan Religiusitas Ibadah dari Orang Tua ke Anak
}

\author{
Tarmilia $^{1}{ }^{\bowtie}$, Daliman $^{1}$ \\ Psikologi, Universitas Muhammadiyah Surakarta, Indonesia(1) \\ DOI: $\underline{10.31004 / o b s e s i . v 6 i 3.1664}$
}

\begin{abstract}
Abstrak
Orang tua seringkali kebingungan menjawab berbagai pertanyaan anak tentang iman dan ibadah. Penelitian ini bertujuan untuk mengetahui gambaran efektivitas model percakapan Nabi Ibrahim AS kepada putranya yang bernama Nabi Ismail AS tentang ibadah kurban, yang dapat diteladani oleh orang tua dalam rangka penanaman ibadah salat dan puasa bagi anak usia dini. Metode penelitian ini studi kasus deskriptif. Pengumpulan data melalui wawancara dan observasi pada tiga bapak yang beragama Islam, tinggal di Boyolali, berpendidikan rendah, serta masing-masing memiliki satu anak berusia 5-6 tahun. Hasil penelitian menunjukkan model percakapan Nabi Ibrahim AS dengan putranya yang bernama Nabi Ismail AS tentang ibadah kurban, efektif untuk menanamkan ibadah salat dan puasa dari orang tua kepada anak usia dini. Temuan percakapan orang tua - anak misalnya Bapak: "Tapi kamu akan puasa?" Anak: “Ya, puasa”. Bapak: “Kuat?” Anak: “Ya, kalau tidak kuat aku bobok.” Bapak: "Alhamdulillah, anak kuat puasa setengah hari. Kalau tidak kuat, minum tidak apa-apa."
\end{abstract}

Kata Kunci: percakapan; religiusitas ibadah; orang tua, anak

\begin{abstract}
Parents are often confused in answering children's questions about faith and worship. This study aims to describe the effectiveness of the conversation model of Prophet Ibrahim AS with Prophet Ismail AS about sacrificial worship, which can be imitated by parents for instilling prayers and fasting for early childhood. The method is a descriptive case study and data collection through interviews and observation with three fathers who are Muslim, live in Boyolali, have low education, and have one child aged 5-6 years. The result is conversational model of Prophet Ibrahim AS with Nabi Ismail AS about sacrificial worship, was effective for instilling prayers and fasting from parents to early childhood. One of the findings Father: "But you will fast?" Child: "Yes fasting". Father: "Strong?" Child: "Yes; if not, I will sleep." Father: "Alhamdulillah, she is strong for half a day. If she is not strong and wants to drink, it's okay."
\end{abstract}

Keywords: conversation; religiosity; parents, child

Copyright (c) 2021 Tarmilia, Daliman

$\triangle$ Corresponding author :

Email Address : s300200001@student.ums.ac.id (Surakarta, Jawa Tengah, Indonesia)

Received 20 March 2021, Accepted 10 August 2021, Published 18August 2021 


\section{PENDAHULUAN}

Syamsudin (2008) mengemukakan bahwa seringkali orang tua terkejut dan bingung untuk menjawab serta menjelaskan pertanyaan anak tentang ajaran agama. Ada berbagai cara orang tua mengenalkan agama pada anak, misalnya dengan menyampaikan cerita, penjelasan, ajakan, dan teladan. Pulungan (2018) mengemukakan terdapat enam cara yang bisa diterapkan dalam mendidik religiusitas Islam anak, yaitu: (1) Meneladani dialog Al Quran dan nabawi; (2) Meneladani kisah dalam Al Qur'an dan nabawi; (3) Meneladani pendidik; (4) Pembiasaan praktik; (5) Mengambil pelajaran dan nasihat; (6) Targhib dan tarhib.

Salah satu cara yang dapat diterapkan dalam mendidik religiusitas Islam, khususnya dalam hal keimanan oleh orang tua kepada anak adalah dengan meneladani percakapan Nabi Ya'qub dan putra-putranya, seperti firman Allah SWT yang artinya: "Adakah kamu hadir ketika Ya'qub kedatangan (tanda-tanda) maut, ketika ia berkata kepada anak-anaknya: "Apa yang kamu sembah sepeninggalku?" Mereka menjawab: "Kami akan menyembah Tuhanmu dan Tuhan nenek moyangmu, Ibrahim, Ismail dan Ishaq, (yaitu) Tuhan Yang Maha Esa dan kami hanya tunduk patuh kepada-Nya."(Q.S. Al-Baqarah (2) ayat 133). Berdasarkan ayat diatas dapat difahami bahwa dialog atau percakapan menjadi hal yang penting bagi orang tua dalam memperkenalkan dan mengajarkan agama.

Callanan \& Oakes (1992) mengemukakan bahwa orang tua diharapkan mampu memberi penjelasan dengan sabar, untuk menjawab keingintahuan anak di bawah tujuh tahun, yang seringkali bertanya tentang iman dan ibadah. Lebih lanjut King \& Boyatzis (2015) mengemukakan bahwa percakapan yang dilakukan dua arah, anak diperbolehkan berpendapat dan bertanya, sedangkan orang tua mendengar, menyampaikan jawaban dan pendapat untuk mentransmisikan ajaran agama. Pengajaran religiusitas lebih berhasil jika kedua orang tua beragama sama (Luria \& Katz, 2019) dan membina hubungan yang hangat dengan anak (Stearns \& Mckinney, 2018). Jalinan kedekatan yang nyaman dengan ibu menjadikan anak merasakan kedekatan dengan Tuhan (Cassibba dkk., 2013; Dalton dkk., 2018). Orang tua hendaknya memberi teladan rajin beribadah dalam kehidupan sehari-hari (Pulungan, 2018) dan berbincang tentang iman (Yust, 2017). Menurut Imam Ghazali (dalam Asy'ari \& M., 2019) orang tua bisa mengajarkan agama dengan memberi teladan, membiasakan, berkisah, permisalan, dan nasihat yaitu dengan menceritakan kisah para Nabi dan sahabat (Sit, 2016).

Secara khusus dalam menanamkan ibadah salat telah diajarkan oleh Rasulullah SAW sebagaimana disebutkan dalam hadits yang diriwayatkan oleh Abu Dawud dan Al- Hakim yaitu bahwa pada anak usia dini hendaklan diperkenalkan dan dibiasakan mengikuti salat dan puasa, dengan harapan usia tujuh tahun anak sudah siap belajar salat dan puasa sesuai syarat dan rukunnya. Orang tua boleh memberikan hukuman pada anak usia sepuluh tahun jika tidak bersedia menjalankan salat (Huliyah, 2016). Pukulan diberikan setelah orang tua menasihati berulang-ulang namun anak tidak taat untuk salat sebagai bentuk hukuman. Pukulan tidak boleh disertai amarah, mencederai atau membuat trauma anak, namun sekedar untuk mendidik saja. Lebih lanjut dikemukakan oleh Leersum-bekebrede dkk. (2019) bahwa orang tua mengajarkan anak beribadah dengan melakukan bersama.

Penelitian Rizky \& Moulita (2017) di daerah Sumatera Utara diperoleh bahwa komunikasi interpersonal sering dilakukan di saat santai untuk mengajarkan ibadah salat dari orang tua kepada anak, sedangkan penelitian Irhamna (2016) pada orang tua siswa MI Darrusalam Kota Bengkulu menemukan bahwa orang tua tidak punya banyak waktu dan pengetahuan agama yang memadai untuk mendampingi dan mengajarkan agama termasuk didalamnya akhlak kepada anak. Orangtua KB-TK An-Nisa Krian Sidoarjo Jawa Timur dalam mengajarkan ibadah kepada anak dengan memberi nasihat, teladan, dan membiasakan dalam keseharian, mengajak anak mengulang-ulang hafalan surah dan doa (Asy'ari \& M., 2019). Hasil penelitian senada didapatkan oleh Trimuliana \& Dhieni, Hapidin (2019) bahwa guru membiasakan siswa Taman Kanak-kanak Ar-Rahman Motik Jakarta untuk berakhlak mulia, berdoa dan ibadah sebagai kegiatan harian di sekolah. 
Religiusitas anak sangat dipengaruhi oleh ajaran orang tua (Trovão, 2017), guru, dan lingkungan (Sulaiman dkk., 2014) termasuk keluarga besar, masyarakat, serta teman. Sekolah dan rumah mempengaruhi perilaku religiusitas anak (Bano \& Ferra, 2018). Guru yang religius akan mengajarkan moral baik pada anak (Qoyyimah, 2016), sedangkan orang tua membimbing anak agar mampu menginternalisasi agama, yaitu anak memilih beribadah karena memahami dan senang, bukan karena dipaksa (Brambilla dkk., 2015).

Salah satu kisah yang bisa untuk diteladani oleh orang tua dalam mengajarkan anak untuk ibadah adalah dengan percakapan Nabi Ibrahim AS dengan putranya Nabi Ismail AS tentang ibadah kurban. Dikisahkan dalam Al Qur'an Surah Ash Shaffat (37) ayat 102 yang Artinya: "Maka tatkala anak itu sampai (pada umur sanggup) berusaha bersama-sama Ibrahim, Ibrahim berkata: "Hai anakku sesungguhnya aku melihat dalam mimpi bahwa aku menyembelihmu. Maka pikirkanlah apa pendapatmu! Ia menjawab: "Hai Bapakku, kerjakanlah apa yang diperintahkan kepadamu; insya Allah kamu akan mendapatiku termasuk orang-orang yang sabar". Nabi Ibrahim AS bertanya tentang pendapat Nabi Ismail AS bukan untuk meminta persetujuan apakah mentaati perintah Allah SWT atau tidak. Keduanya adalah Nabi yang taat kepada perintah Allah SWT dalam keadaan apapun. Pertanyaan itu hanya untuk mengetahui keteguhan hati anak dalam menerima perintah dari Allah SWT (Zainab, 2017). Nabi Ibrahim AS mendapat perintah dari Allah SWT untuk mengurbankan Nabi Ismail AS sebagai bentuk ketaatan. Nabi Ismail AS dengan sopan dan lemah lembut menjawab bahwa ia bersedia disembelih oleh ayahnya demi mentaati perintah Allah SWT.

Dijelaskan oleh (Zainab, 2017) bahwa dalam melakukan percakapan ibadah dengan putranya, Nabi Ibrahim AS menggunakan tahapan: (1) Membentuk kebersamaan dan kepercayaan. Dapat dipahami dari Al Qur'an yaitu Surah Ash Shafat ayat 102 bahwa Nabi Ismail membantu ayahnya mencari nafkah. Sehingga hubungan keduanya dekat. Terjalin kebersamaan dan kepercayaan antar ayah dan anak, dan (2) Membina Komunikasi yang Baik. Nabi Ibrahim AS memberi teladan kepada umatnya bagaimana berkomunikasi yang baik dengan anak. Komunikasi yang baik seperti diteladankan oleh Nabi Ibrahim AS memiliki ciri sebagai berikut: (a) Komunikasi dua arah; (b) Komunikasi penuh keterbukaan. Nabi Ibrahim terbuka bahwa ia diperintah Allah SWT untuk menyembelih putranya. Beliau memberi kesempatan pada Ismail untuk terbuka menyatakan pendapatnya. Ismail mau terbuka bahwa dia sabar menerima perintah Allah SWT, dan (c) Percakapan penuh empati. Ayah menggunakan bahasa yang lemah lembut menanyakan keteguhan hati anak. Anak berempati bahwa ayahnya hanya menjalankan perintah Allah SWT, bukan karena marah atau benci pada anak karena mau menyembelihnya.

Selanjutnya (Zainab, 2017) mengemukakan pelajaran yang bisa diambil dari model percakapan ibadah Nabi Ibrahim AS dengan putranya, Nabi Ismail AS yaitu: (1) Pentingnya orang tua dan anak saling menghargai dan menghormati dalam percakapan agar berhasil mencapai tujuan komunikasi. Nabi Ibrahim AS berkenan menanyai pendapat Nabi Ismail AS. Nabi Ismail AS berlapang dada menyadari bahwa ayahnya diperintah oleh Allah SWT, dan (2) Pentingnya memilih kalimat dan cara berkomunikasi yang sesuai dengan tingkat perkembangan anak. Nabi Ismail AS dipanggil Nabi Ibrahim AS wahai anakku dengan penuh kelembutan. Nabi Ibrahim dipanggil Nabi Ismail AS wahai ayahku. Anak menjadi paham maksud pembicaraan ayah.

Peristiwa tersebut terjadi ketika Nabi Ismail AS telah berusia remaja akhir (ghulam). Model percakapan antara Nabi Ibrahim AS dengan Nabi Ismail AS perlu disesuaikan dengan tahap perkembangan kognitif dan moral jika diterapkan pada anak usia dini. Sebagaimana diajarkan oleh Rasulullah SAW dalam sebuah hadits yang artinya: "Berbicaralah kepada manusia sesuai dengan kadar akal (intelektualitas) mereka" (H.R. Muslim). Orang tua berbicara dengan perkataan yang mudah dipahami (Qaulan Maysura) anak. Sebagaimana yang diajarkan dalam ayat berikut yang artinya: "Dan jika kamu berpaling dari mereka untuk memperoleh rahmat dari Tuhannya yang kamu harapkan, maka katakanlah kepada mereka Qaulan Maysura-ucapan yang mudah" (Q.S. Al-Isra (17): 28). Berdasarkan cara di atas anak bisa memahami maksud 
pembicaraan orang tua (Husen, 2017). Nabi Ibrahim AS berhasil mendidik dan mengajak putranya agar taat beribadah pada Allah SWT dengan metode percakapan. Keduanya rela berkurban kepada Allah SWT. Nabi Ibrahim AS rela kehilangan putra kesayangan dan Nabi Ismail AS rela kehilangan nyawa demi memenuhi perintah Allah SWT. Telah banyak penelitian tentang pola komunikasi orang tua dengan anak untuk mengajarkan agama, namun penelitian yang akan dilakukan ini akan berbeda dengan penelitian-penelitian sebelumnya, yang akan meneliti tentang efektifitas model percakapan Nabi Ibrahim AS dengan Nabi Ismail AS untuk menanamkan religiusitas ibadah anak usia dini.

Berdasarkan uraian diketahui bahwa banyak usaha yang telah dilakukan oleh orang tua yang berupa komunikasi interaktif untuk menanamkan religiusitas ibadah bagi anak. Salah satu usaha komunikasi interaktif dalam penanaman religiusitas bagi anak tersebut adalah melalui model percakapan Nabi Ibrahim AS kepada putranya yang bernama Nabi Ismail AS tentang ibadah kurban. Sehubungan dengan hal di atas dikemukakan rumusan masalah penelitian ini adalah "Bagaimana gambaran efektivitas model percakapan Nabi Ibrahim AS kepada putranya yang bernama Nabi Ismail AS tentang ibadah kurban, yang dapat diteladani oleh orang tua dalam rangka penanaman ibadah salat dan puasa bagi anak usia dini?". Berdasarkan rumusan masalah di atas, maka dikemukakan tujuan penelitian ini adalah untuk mengetahui bagaimana gambaran efektivitas model percakapan Nabi Ibrahim AS kepada putranya yang bernama Nabi Ismail AS tentang ibadah kurban, yang dapat diteladani oleh orang tua dalam rangka penanaman ibadah salat dan puasa bagi anak usia dini. Penelitian ini penting dilakukan sebagai pijakan bagi guru dalam memberikan program penyuluhan bagi orang tua dalam melakukan percakapan religiusitas ibadah dengan anak yang sesuai dengan teori perkembangan kognitif dan moral anak sehingga membantu orang tua mengenalkan dan membiasakan anak beribadah sejak usia dini.

\section{METODOLOGI}

Penelitian ini merupakan studi kasus yang melibatkan 3 informan, dengan tujuan ingin mengetahui bagaimana model atau gambaran percakapan orang tua dengan anak untuk menanamkan religiusitas ibadah, sebagaimana dicontohkan dalam percakapan Nabi Ibrahim AS dengan Nabi Ismail AS. Teknik pengumpulan data dengan wawancara semi terstruktur dan observasi partisipan. Peneliti berposisi sebagai instrumen kunci sebagai pengumpul data dan mengetahui keadaan lapangan, karena berada di lokasi yang berdekatan dengan ketiga informan. Saat wawancara, peneliti sekaligus mengobservasi percakapan anak dengan ayah dan atau ibu di rumah. Penelitian ini dilaksanakan di wilayah Kabupaten Boyolali Propinsi Jawa Tengah. Wawancara dilakukan secara tatap muka di rumah informan yang dilanjutkan pesan suara di aplikasi Whatsapp melalui telepon seluler, pada tanggal 1 - 14 Mei 2021 bersamaan dengan bulan Ramadlan tahun $1442 \mathrm{H}$. Data informan suami dapat dilihat di Tabel 1, sedangkan data informan istri dapat dilihat di Tabel 2.

Berdasarkan data tabel 1 dan 2 diketahui bahwa tiga orang suami beragama Islam, berusia relatif sama yaitu 30 tahunan, pekerjaan swasta, berpendidikan rendah, masingmasing memiliki seorang anak yang bersekolah di Taman Kanak-Kanak, sedangkan tiga orang istri masing-masing beragama Islam, hanya satu yang berpendidikan tinggi dan bekerja sebagai karyawan swasta, dua istri lainnya berpendidikan rendah dan seorang sebagai ibu rumah tangga, seorang lainnya membantu suami menyiapkan dagangan di rumah.

Tabel 1. Demografi Suami

\begin{tabular}{cccccccc}
\hline $\begin{array}{c}\text { Nama } \\
\text { suami }\end{array}$ & Agama & $\begin{array}{c}\text { Usia } \\
\text { (tahun) }\end{array}$ & Pekerjaan & Pendidikan & $\begin{array}{c}\text { Jumlah } \\
\text { anak }\end{array}$ & $\begin{array}{c}\text { Usia } \\
\text { Anak (Tahun) }\end{array}$ & $\begin{array}{c}\text { Jenis kelamin } \\
\text { anak }\end{array}$ \\
\hline WO & Islam & 32 & Wiraswasta & SD & 1 & 6 & Perempuan \\
EW & Islam & 31 & Buruh pabrik & SMP & 1 & 6 & Perempuan \\
AD & Islam & 36 & Wiraswasta & SMP & 1 & 5 & Laki-laki \\
\hline
\end{tabular}


Tabel 2. Demografi Istri

\begin{tabular}{llllll}
\hline Nama Suami & Nama & Agama & Usia (tahun) & Pekerjaan & Pendidikan \\
\hline WO & $R I$ & Islam & 26 & Wiraswasta & SMP \\
EW & $D N$ & Islam & 27 & Ibu rumah tangga & SMP \\
AD & TR & Islam & 34 & Swasta & D3 \\
\hline
\end{tabular}

Data dianalisis dengan langkah-langkah sebagai berikut yaitu menyiapkan data, menarik kategori dan tema, kemudian menarasikan dan memvisualisasikan, memaknai dan merefleksikan secara personal dan literatur, lalu memvalidasi temuan (Creswell, 2012), adapun desain penelitian dapat dilihat di gambar 1 .

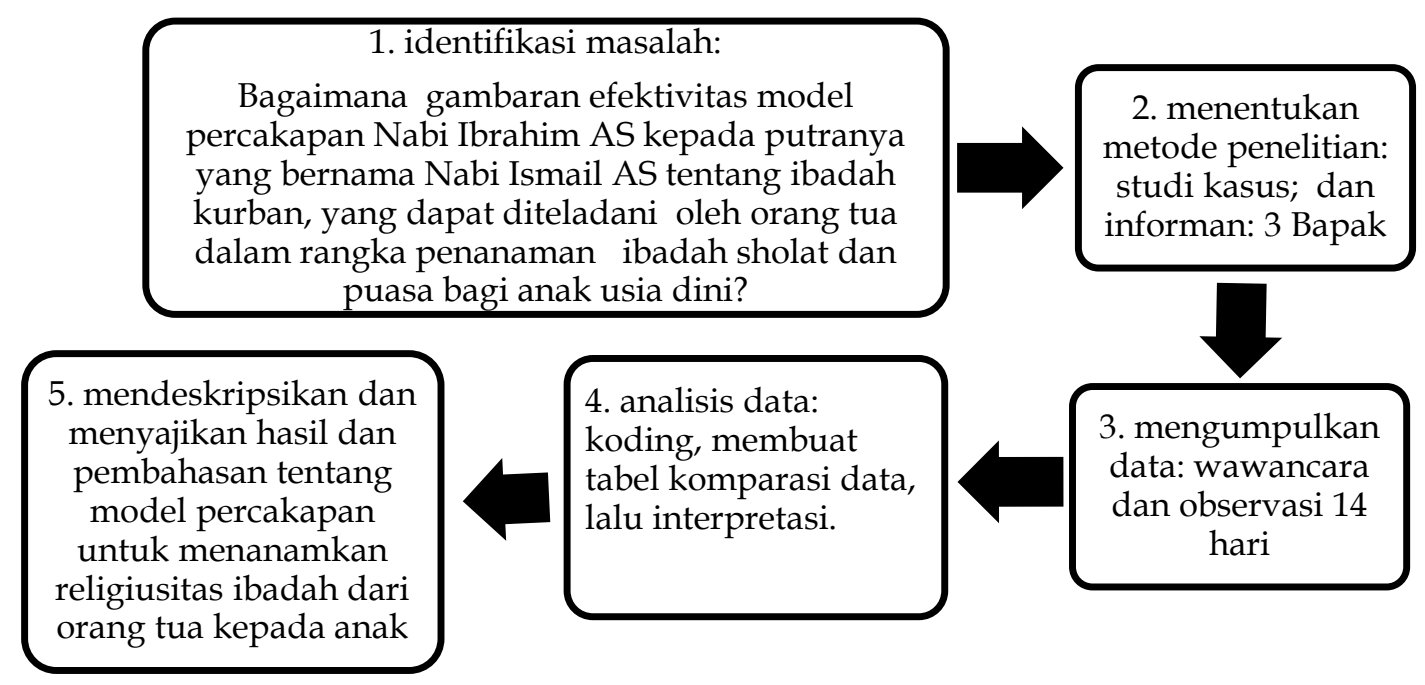

\section{Gambar 1. Desain Penelitian}

\section{HASIL DAN PEMBAHASAN}

Hasil analisis data didapat dua tema dalam penelitian ini yaitu: (1) Membentuk kebersamaan dan kepercayaan; (2) membangun komunikasi yang baik. Kedua tema dijelaskan lebih detail sebagai berikut:

\section{Membentuk kebersamaan dan kepercayaan}

Orang tua berusaha membentuk kebersamaan dan kepercayaan dengan anak karena memiliki harapan dan menganggap penting pada religiusitas anak di masa depan. Kebersamaan dengan keluarga menjadikan anak senang hati mengenal dan menerima ajaran agama (Handayani, 2016; Dalton, dkk., 2018), juga beribadah (Leersum-bekebrede, dkk., 2019). Orang tua ingin anaknya masuk surga kelak (Bunnell, dkk., 2018).

EW (b. 16-17) penting agar anak bersyukur bisa membahagiakan orang tua.

WO (b.185) Penting sekali anak beriman dan beribadah supaya di akhirat selamat.

$A D$ (b.93-94) Sangat penting, karena itu pondasi, manusia harus beriman, karena manusia harus percaya Penciptanya.

Orang tua membangun kebersamaan dengan anak menjalankan ibadah puasa Ramadhan dengan mengajak anak ikut sahur dan berbuka puasa. Dilanjutkan salat berjemaah.

EW (b. 58) Saat buka saat sahur ikut makan. Anak diajak ke masjid salat berjemaah

WO (b. 189) Kalau di masjid tidak pernah

$A D$ (b. 90-91) Sejak usia dua tahun sudah diajari. Dibiasakan ikut sholat diajak ngaji. Anak mengikuti sholat sebentar terus mainan sendiri

Orang tua menjalin kebersamaan dengan keluarga dengan meluangkan waktu khusus untuk bersantai bersama keluarga. Biasanya mereka berbincang sesudah sholat magrib 
DOI: 10.31004/obsesi.v6i3.1664

sampai sebelum tidur. Sebelum tidur keluarga mengobrol dan saling bertanya jawab (Callanan \& Oakes, 1992).

$A D$ (b. 155-158) Kalau mau tidur pasti ngobrol tentang agama, kalau tidak salat itu dosa, kalau tidak ngaji nanti tidak bisa memberi surga Bapak dan Ibu.

Dalam kesempatan tersebut orang tua sekaligus menambah hafalan anak.

EW (b. 9-10) Waktu mau tidur baca-baca surah, waktu kita salat berjemaah anak pelanpelan mengikuti, tidak harus langsung bisa.

Namun satu bapak tidak memiliki waktu khusus untuk mengobrol dengan anak masalah iman dan ibadah.

WO (b. 201) Saya jarang dengar anak bercerita atau bertanya pada ibu. Kalau di kamar tanyanya apa, saya tidak dengar.

Di masa pandemi Covid-19 keluarga tidak leluasa bepergian dan beraktifitas di tempat umum, namun demikian menurut ketiga bapak, kesempatan bercakap-cakap dengan anak tetap tidak bisa leluasa.

$A D$ (b. 167-170) Di masa pandemi kalau menurut saya sama saja. Tidak ada bedanya. Karena kami orang tua punya kerjaan sendiri yang waktunya tidak menentu.

Orang tua memberikan teladan beriman dan beribadah kepada Allah SWT agar anak percaya pada orang tua. Dua bapak dan istri senantiasa menjalankan salat wajib lima waktu. Sedangkan satu Bapak mengatakan salat dalam sehari tidak mencapai lima kali. Beda dengan istrinya yang rajin melaksanakan salat lima waktu.

AD (b.96) Alhamdulillah saya dan istri salat lima waktu.

EW (b. 19) Ya, kami sekeluarga sholat 5 waktu

WO (b. 187) Ya kadang melaksanakan salat tapi bolong-bolong.

Religiusitas orang tua juga terlihat dari ketaatan beliau salat berjemaah di masjid.

Orang tua menceritakan bahwa mereka setiap hari ke masjid, walau tidak genap sehari lima kali. Namun satu bapak berkata bahwa beliau tidak pernah ke masjid.

$A D$ (b. 98) Kalau tidak sibuk sendiri, sehari 4 kali kadang 3 kali salat ke masjid.

WO (p. 189) Kalau di masjid tidak pernah.

Orang tua berpuasa di bulan Ramadhan.

EW (b. 23) Ya, kami sekeluarga berpuasa.

$A D(b .100)$ Alhammdulillah saya dan istri ya puasa ramadhan.

Sedangkan satu bapak tidak berpuasa karena sibuk tapi istri beliau berpuasa.

WO (b. 191) Untuk saat ini saya tidak puasa karena sibuk

Orang tua membaca Al Qur'an bersama keluarga.

$E W(b .25-26)$ kami sekeluarga ngaji.

$A D$ (b. 102) Alhamdulillah setiap hari ngaji, saya bisa lancar membaca Al Qur'an

Satu bapak belum bisa lancar membaca Al Qur'an. Beliau tidak rutin mengaji.

WO (b. 193) Saya sedikit-sedikit bisa membaca Al Qur'an, membaca seminggu paling satu kali.

Anak bapak tersebut diajari membaca Iqra' oleh ibunya.

WO (b. 211-212) Ceritanya Ibu menyuruh anak belajar puasa tapi anaknya belum mau...dan ibunya juga mengajak untuk membaca iqra, sedikit demi sedikit mau.

Dari tabel 3 didapatkan gambaran bahwa ketiga bapak menganggap penting agar anak memiliki iman dan rajin ibadah. Seorang bapak kurang membangun kebersamaan dan kepercayaan pada anak. Ia tidak memiliki waktu khusus untuk berbincang bersama keluarga tentang iman dan ibadah. Beliau tidak melaksanakan ibadah secara rutin. Ia tidak berpuasa dan tidak salat berjemaah bersama keluarga. Dua orang bapak membangun kebersamaan dan kepercayaan kepada anak. Keduanya rutin salat baik di rumah maupun ke masjid. Mereka salat berjemaah bersama istri dan anak. Kedua bapak meluangkan waktu untuk bercengkerama dengan anak dan istri tentang iman dan ibadah, terutama dengan anak. Keduanya juga berpuasa bersama istri dan anak. 
Tabel 3. Komparasi Hasil Wawancara Tema Membentuk Kebersamaan Dan Kepercayaan

\begin{tabular}{|c|c|c|c|c|}
\hline \multirow[t]{2}{*}{ Sub tema } & \multicolumn{3}{|c|}{ Informan } & \multirow[t]{2}{*}{ Interpretasi } \\
\hline & WO & EW & AD & \\
\hline $\begin{array}{l}\text { Pentingnya } \\
\text { penanaman iman } \\
\text { dan kebiasaan } \\
\text { ibadah }\end{array}$ & $\begin{array}{l}\text { Penting } \\
\text { (b.185) }\end{array}$ & $\begin{array}{l}\text { Penting } \\
\text { (b. 16-17) }\end{array}$ & $\begin{array}{l}\text { Penting } \\
\text { (b.93-94) }\end{array}$ & Penting \\
\hline \multicolumn{5}{|c|}{ Membangun kebersamaan: } \\
\hline $\begin{array}{l}\text { Meluangkan waktu } \\
\text { khusus untuk } \\
\text { bercakap-cakap } \\
\text { tentang ibadah } \\
\text { dengan anak }\end{array}$ & $\begin{array}{l}\text { Tidak } \\
\text { bersedia } \\
\text { (b. 201) }\end{array}$ & $\begin{array}{l}\text { Bersedia } \\
\text { (b. 9-10) }\end{array}$ & $\begin{array}{l}\text { Bersedia } \\
\text { (b. 155-158) }\end{array}$ & $\begin{array}{l}\text { EW dan AD mau meluangkan } \\
\text { waktu, sementara WO tidak } \\
\text { bersedia. }\end{array}$ \\
\hline $\begin{array}{l}\text { Salat berjemaah } \\
\text { dengan keluarga }\end{array}$ & $\begin{array}{l}\text { Tidak } \\
\text { (b. 189) }\end{array}$ & $\begin{array}{l}\text { Ya } \\
\text { (b. 58) }\end{array}$ & $\begin{array}{l}\text { Ya } \\
\text { (b. 90-91) }\end{array}$ & $\begin{array}{l}\text { EW dan AD salat berjamaah dengan } \\
\text { keluarga baik di rumah atau di } \\
\text { masjid, sedangkan WO tidak. }\end{array}$ \\
\hline $\begin{array}{ll}\text { Puasa } & \text { bersama } \\
\text { sekeluarga } & \\
\end{array}$ & $\begin{array}{l}\text { Tidak } \\
\text { (b. 191) }\end{array}$ & $\begin{array}{l}\text { Ya } \\
\text { (b. 23) }\end{array}$ & $\begin{array}{l}\mathrm{Ya} \\
\text { (b. 100) }\end{array}$ & $\begin{array}{l}\text { EW dan AD puasa bersama } \\
\text { keluarga, sementara WO tidak. }\end{array}$ \\
\hline \multicolumn{5}{|c|}{ Membangun kepercayaan: } \\
\hline Bapak salat rutin & $\begin{array}{l}\text { Tidak } \\
\text { selalu } \\
\text { (b. 187) }\end{array}$ & $\begin{array}{l}\text { Ya } \\
\text { (b. 19) }\end{array}$ & $\begin{array}{l}\text { Ya } \\
\text { (b.96) }\end{array}$ & $\begin{array}{l}\text { EW dan AD rutin salat lima waktu } \\
\text { sedangkan WO tidak selalu. }\end{array}$ \\
\hline $\begin{array}{ll}\text { Bapak puasa } \\
\text { Ramadan }\end{array}$ & $\begin{array}{l}\text { Tidak } \\
\text { (b. 191) }\end{array}$ & $\begin{array}{l}\text { Ya } \\
\text { (b. 23) }\end{array}$ & $\begin{array}{l}\text { Ya } \\
(\text { b. 100) }\end{array}$ & $\begin{array}{l}\text { EW dan AD rutin puasa Ramadan, } \\
\text { sedangkan WO tidak }\end{array}$ \\
\hline $\begin{array}{l}\text { Bapak bisa dan rutin } \\
\text { membaca Al Quran }\end{array}$ & $\begin{array}{l}\text { Sedikit, } \\
\text { kadang } \\
\text { (b. 193) }\end{array}$ & $\begin{array}{l}\text { Ya, sering } \\
\text { (b. 25-26) }\end{array}$ & $\begin{array}{l}\text { Ya, rutin } \\
\text { (b. 102) }\end{array}$ & $\begin{array}{l}\text { AD dan EW lancar membaca Al } \\
\text { Quran, sedangkan WO tidak }\end{array}$ \\
\hline
\end{tabular}

\section{Membangun komunikasi yang baik}

Komunikasi yang terbangun baik mempermudah orang tua mengenalkan ibadah pada anak. Anak usia 5-6 tahun bisa dilatih salat dan zakat (Asy'ari \& M., 2019), mengucap salam, hafalan doa dan surah pendek, menghafal bacaan dan gerakan salat, shodaqoh, mendoakan orang tua dan kaum muslimin (Trimuliana, Dhieni, \& Hapidin, 2019). Anak boleh bercerita dan menyampaikan pendapat lalu orang tua menanggapi. Orang tua tidak mendominasi percakapan agar anak mau melanjutkan mengobrol (Fasoli \& Lozano, 2019) dan saling aktif bertanya jawab (Subqi, 2016). Percakapan antara orang tua dan anak tentang agama bisa terjadi kapanpun dan di manapun (Boyatzis \& Janick, 2003) atau meluangkan waktu khusus. Komunikasi yang baik yang diteladankan oleh Nabi Ibrahim AS dengan Nabi Ismail AS yaitu komunikasi yang berlangsung dua arah, penuh keterbukaan, dan penuh empati.

Orang tua dan anak melakukan komunikasi yang baik (Umroh, 2019) yaitu berlangsung dua arah, menggunakan strategi interaktif, saling bertanya, berpendapat, mendengar, dan memberi tanggapan (Handayani, 2016).

EW (b. 43-46) Kalau puasa anak tiap pagi bertanya Pak kok ada yang teriak sahur

apa itu? Itu tanda makan pagi, Anak bilang: "kalau begitu aku ikut makan".

Bapak: "Tapi kamu akan puasa?" Anak: "Ya puasa". Bapak: "Kuat?" Anak:

"ya, kalau tidak kuat aku bobok." Alhamdulillah, kuat setengah hari. Kalo tidak kuat minum tidak apa-apa".

Sayangnya satu bapak tidak melakukan komunikasi dengan anak.

WO (b. 208-209) Anak tidak bertanya tentang tata cara salat, saya tidak pernah menjelaskan, dan anak tidak tanya.

Anak bertanya tentang tata cara salat dan orang tua menjelaskan dengan lemah lembut. 
DOI: 10.31004/obsesi.v6i3.1664

EW (b. 28-29) Anak bertanya kok kenapa gerakannya gitu-gitu. Anak lama-lama mengikuti gerakan kami berdua, lalu sedikit sedikit mengikuti

Orang tua menjawab pertanyaan anak tujuan salat.

$A D$ (b. 115-116) anak juga bertanya: "Kok salat terus, kenapa?" Bapak: "Kewajiban manusia itu salat karena sudah diperintah begitu."

Satu bapak tidak ditanyai anaknya perihal kenapa harus salat dan bagaimana tata cara salat.

WO (b. 208) Anak tidak pernah bertanya kenapa harus salat.

Komunikasi hanya berjalan satu arah dari bapak tersebut ke anak.

WO (b. 206) Kalau anak tidak sholat saya negur, sholat dulu nak, sudah adzan, anak: "Ya, nanti saya ikut sama ibu."

Jika anak tidak mau salat orang tua berusaha membujuk anak terlebih dahulu, tidak mengancam atau menakuti.

EW (b. 60-61) Dirayu-rayu dulu, ayo salat dulu! Kalau tidak mau dibilangi nanti dimarahi bu guru lho, nanti dimarahi Allah lho.

Satu bapak dan istrinya berusaha memotivasi anak berpuasa dengan hadiah boleh makan kue lebaran jika berpuasa.

EW (b. 48-52) Bapak: "Iya, semua orang yang tidak puasa tidak boleh makan roti lebaran, itu khusus bagi orang yang puasa." Anak: "Ya sudah aku puasa agar boleh ikut makan roti lebaran". Sampai kini ikut puasa.

Satu bapak sedikit menjelaskan tentang puasa pada anak. Anaknya disuruh puasa tapi belum mau.

WO (b. 195) Anak bertanya puasa itu apa. Jawaban saya ya puasa itu bulan yang suci wajib puasa.

WO (b. 211-212) Ibu menyuruh anak belajar puasa tapi anaknya belum mau

Tentang hal-hal yang membatalkan puasa, orang tua berusaha agar dipahami anak, sayangnya penjelasan tersebut ada yang tidak sesuai dengan konsep dari ajaran Islam.

EW (b. 66) Iya, yang membatalkan puasa minum, makan, nangis, marah-marah.

Kalau anak tidak berpuasa Bapak tidak memaksa. Karena memang anak belum kuat.

EW (b. 63-64) Kalau anak tidak puasa, saya tidak memaksa.

Anak yang akrab dengan orang tua berani bertanya, berpendapat, dan mengingatkan orang tua.

EW (b. 37) Anak kadang mengingatkan: "Bapak sudah azan, ayo, salat!"

Komunikasi berlangsung penuh keterbukaan. Orang tua memberi kesempatan anak mengungkapkan perasaan dan pendapat (Handayani, 2016), tidak mendominasi percakapan.

AD (b. 118-120) Anak: "Kok puasa, kan lapar?" Bapak: "Puasa agar kita belajar sabar, menahan marah." Puasa belum begitu paham. "Kalau puasa kok sampai satu hari, siang tidak boleh makan?" Bapak: "kalau anak kecil puasa setengah hari dulu, biar perutnya tidak sakit, boleh makan dulu."

Anak bapak tersebut bersedia ikut puasa.

AD (b. 124) Alhamdulillah puasa setengah hari

Orang tua penuh empati pada anak. Penggunaan bahasa yang lemah lembut dan penuh perhatian dari orang tua mempengaruhi keberhasilan penanaman pengetahuan agama pada anak (Rizky \& Moulita, 2017).

EW (b. 74-75) Saya memberikan pemahaman baru seperti itu. Karena pola pikir seusia anak saya kalau terperinci belum paham. Nanti kalau sudah besar saya jelaskan perlahan-lahan bersama istri saya.

Satu bapak sedikit berbincang dengan anak dan tidak terlalu tahu apakah anak berbincang dengan ibunya tentang ibadah salat dan puasa.

WO (b. 201) Saya jarang dengar anak bercerita atau bertanya pada ibu. Kalau di kamar tanyanya apa, saya tidak dengar.

Orang tua memahami tingkat berfikir anak masih terbatas. Karenanya orang tua berusaha memilih teknik dan kalimat yang tepat untuk menyampaikan keimanan pada yang ghaib. 
EW (b. 32-36) Karena salat itu wajib bagi umat Islam. Tapi anak belum bisa menerima. Maka pertama dibilangin di atas panas, biar dingin main air kita wudu, salat. Neraka panas.

AD (b. 104-106) Saya ajak dik ayo salat biar disayang Allah. Anak bertanya:"Allah itu siapa?" Bapak:"Allah itu Pencipta kita". Anak: "Allah itu di mana?" Bapak: "Allah itu di hati kita masing-masing." Anak: "Kalau disayang Allah?" Bapak:" Ya masuk surga". Terus mau salat, yang penting mau dulu.

Namun satu bapak tidak menjelaskan dan anak tidak bertanya.

WO (b. 203-204) Anak tidak pernah bertanya tentang Allah siapa, Allah itu apa.

Hanya saja kadang orang tua merasa kesulitan menjawab pertanyaan anak karena merasa kurang dalam pengetahuan agama. Bapak yang tahu ilmu agama bisa menjawab pertanyaan anak.

$A D$ (b. 145-147) Saya sering dengar anak bertanya surga itu ada di mana neraka ada di mana, ibu jawab: "Bertanya pada Bapak. Ibu bisanya jawab yang gampang, kalau masalah begitu yang tahu Bapak."

AD (b. 160-162) Alhamdulillah bisa menjawab pertanyaan anak. Tidak kesulitan.

Tabel 4. Komparasi Hasil Wawancara Tema Membangun Komunikasi Yang Baik

\begin{tabular}{|c|c|c|c|c|}
\hline \multirow{2}{*}{ Sub tema } & \multicolumn{3}{|c|}{ Informan } & \multirow{2}{*}{ Interpretasi } \\
\hline & WO & EW & AD & \\
\hline \multicolumn{5}{|c|}{ Komunikasi dua arah: } \\
\hline $\begin{array}{l}\text { Melakukan } \\
\text { percakapan } \\
\text { tentang salat }\end{array}$ & $\begin{array}{l}\text { Tidak } \\
\text { (b. 208-209) }\end{array}$ & $\begin{array}{l}\text { Ya } \\
\text { (b. 28-29) }\end{array}$ & $\begin{array}{l}\text { Ya } \\
\text { (b. 115-116) }\end{array}$ & $\begin{array}{l}\text { EW dan AD melakukan percakapan } \\
\text { dua arah dengan anak tentang salat, } \\
\text { sedangkan WO tidak. }\end{array}$ \\
\hline $\begin{array}{l}\text { Melakukan } \\
\text { Percakapan } \\
\text { tentang puasa }\end{array}$ & $\begin{array}{l}\text { Ya } \\
\text { (b. 195) }\end{array}$ & $\begin{array}{l}\text { Ya } \\
\text { (b. 43-46) }\end{array}$ & $\begin{array}{l}\text { Ya } \\
\text { (b. 118-120) }\end{array}$ & $\begin{array}{l}\text { WO, EW, dan AD melakukan } \\
\text { percakapan dua arah dengan anak } \\
\text { tentang puasa. }\end{array}$ \\
\hline \multicolumn{5}{|c|}{ Komunikasi berlangsung penuh keterbukaan: } \\
\hline $\begin{array}{l}\text { Melakukan } \\
\text { percakapan } \\
\text { tentang salat }\end{array}$ & $\begin{array}{l}\text { Tidak } \\
\text { (b. 208-209) }\end{array}$ & $\begin{array}{l}\text { Ya } \\
\text { (b. 32-36) }\end{array}$ & $\begin{array}{l}\text { Ya } \\
\text { (b. 104-106) }\end{array}$ & $\begin{array}{l}\text { EW dan AD bercakap penuh } \\
\text { keterbukaan dengan anak tentang } \\
\text { salat, sedangkan WO tidak. }\end{array}$ \\
\hline $\begin{array}{l}\text { Melakukan } \\
\text { percakapan } \\
\text { tentang puasa }\end{array}$ & $\begin{array}{l}\text { Sedikit } \\
\text { keterbukaan } \\
\text { (b. 195) }\end{array}$ & $\begin{array}{l}\text { Ya } \\
\text { (b. 53-56) }\end{array}$ & $\begin{array}{l}\text { Ya } \\
\text { (b. 118-120) }\end{array}$ & $\begin{array}{l}\text { EW dan AD bercakap penuh } \\
\text { keterbukaan dengan anak tentang } \\
\text { puasa, sedangkan WO hanya sedikit } \\
\text { keterbukaannya. }\end{array}$ \\
\hline $\begin{array}{l}\text { Berlangsung } \\
\text { penuh empati }\end{array}$ & $\begin{array}{l}\text { Kurang } \\
\text { (b. 203-204) }\end{array}$ & $\begin{array}{l}\text { Ya } \\
\text { (b. 74-75) }\end{array}$ & $\begin{array}{l}\text { Ya } \\
\text { (b. 104-106) }\end{array}$ & $\begin{array}{l}\text { Dalam berkomunikasi dengan anak } \\
\text { tentang salat dan puasa, AD dan EW } \\
\text { berusaha menyesuaikan tingkat } \\
\text { berpikir anak, sedangkan WO } \\
\text { kurang. }\end{array}$ \\
\hline
\end{tabular}

Dari tabel 4 bisa diketahui bahwa dua bapak melakukan komunikasi secara dua arah, terbuka, dan penuh empati pada anak tentang salat dan puasa, sedangkan satu bapak kurang melakukan percakapan dua arah, keterbukaan, dan empati pada anak tentang salat dan puasa.

Orang tua ketika melakukan percakapan ibadah, hendaknya memahami bahwa anak memiliki perkembangan tingkat berpikir sesuai usianya sebagaimana teori perkembangan kognitif Piaget (dalam King, 2011) yang menjelaskan bahwa anak usia dini masuk dalam tahap pre-operasional yaitu umur 2 sampai 7 tahun. Anak mulai menggunakan simbol-simbol dengan kata, imajinasi, dan menggambar. Anak belum bisa berpikir abstrak. Anak juga belum bisa menerima penjelasan yang rumit. Anak mulai bisa mendeskripsikan suatu objek dengan menggunakan kata-kata dan imajinasi. Anak masih berpusat pada dirinya (egosentris). Pada usia 5-6 tahun, anak pada tahap pikiran anthromorphis yaitu mengimajinasikan Tuhan seperti halnya manusia (Boyatzis, 2013; Sit, 2016). Karenanya, orang tua memberi senyum dan 
perhatian pada pertanyaan anak, serta menjawab secukupnya. Beri anak pujian karena pintar bertanya. Beri alasan ibadah sesuai egosentris anak, misalnya salat agar disayang Allah.

Perkembangan kognitif anak tentang konsep Tuhan berkaitan erat dengan perkembangan moral. Lawrence Kohlberg (dalam King, 2011) mengemukakan bahwa anak usia dini ada pada tahap moral pre konvensional. Anak mentaati aturan karena ingin mendapat hadiah atau takut mendapat hukuman dari orang tua. Mereka belum bisa membedakan baik dan buruk. Sesuai dengan ajaran Islam bahwa anak usia di bawah tujuh tahun belum mumayiz. Dia belum bisa berfikir membedakan yang baik dan buruk dan belum bisa memahami sebab akibat (Sulaiman dkk., 2014).

Tabel 5. Komparasi Hasil Wawancara Kesediaan Anak Beribadah Salat dan Puasa

\begin{tabular}{|c|c|c|c|c|}
\hline \multirow[t]{2}{*}{ Ibadah } & \multicolumn{3}{|c|}{ Informan } & \multirow{2}{*}{ Interpretasi } \\
\hline & WO & EW & AD & \\
\hline $\begin{array}{l}\text { Anak bersedia } \\
\text { melaksanakan } \\
\text { salat }\end{array}$ & $\begin{array}{l}\text { Ya, dengan ibu } \\
\text { (b. 206) }\end{array}$ & $\begin{array}{l}\text { Ya, bersedia } \\
\text { (b. 28-29) }\end{array}$ & $\begin{array}{l}\text { Ya bersedia } \\
\text { (b. 104-106) }\end{array}$ & $\begin{array}{l}\text { Anak Bapak WO, } \\
\text { EW, dan AD } \\
\text { sudah bersedia } \\
\text { salat. }\end{array}$ \\
\hline $\begin{array}{l}\text { Anak bersedia } \\
\text { melaksanakan } \\
\text { puasa }\end{array}$ & $\begin{array}{l}\text { Belum bersedia } \\
\text { (b. 211-212) }\end{array}$ & $\begin{array}{l}\text { Ya, bersedia } \\
\text { (b. 43-46) }\end{array}$ & $\begin{array}{l}\text { Ya, bersedia } \\
\text { (b. 124) }\end{array}$ & $\begin{array}{l}\text { Anak Bapak WO } \\
\text { belum ikut } \\
\text { berpuasa, } \\
\text { sedangkan anak } \\
\text { Bapak EW dan } \\
\text { AD bersedia } \\
\text { puasa }\end{array}$ \\
\hline
\end{tabular}

Dari tabel 5 bisa dikatakan bahwa istri Bapak WO berhasil menanamkan religiusitas ibadah salat kepada anak. Tetapi beliau belum berhasil menanamkan religusitas ibadah puasa kepada anak sedangkan Bapak EW dan AD berhasil menanamkan religiusitas ibadah salat dan puasa kepada anak.

Bapak menyuruh anak salat namun beliau tidak rutin salat. Anak mau salat karena mengikuti ibunya. Anak tidak mau disuruh puasa karena bapak tidak puasa. Anak mau melakukan ibadah salat dan puasa jika dilakukan bersama-sama orang tua bukan sekedar disuruh. Gustanti (2017) mengungkapkan dari penelitian pada keluarga di Kelurahan Labuhan Ratu Raya Kecamatan Labuhan Ratu Bandar Lampung ada orang tua yang hanya menyuruh anak namun dirinya sendiri tidak melakukan sehingga anak enggan melaksanakan salat. Lain halnya pada orang tua yang berkomunikasi dan membersamai anak beribadah maka anak senang hati melakukannya. Lestari (2018) mengungkapkan dari penelitian di Yayasan Yatim Piatu Kemala Puji Bandar Lampung bahwa dengan menerapkan strategi komunikasi, pengasuh berhasil menanamkan ibadah salat pada anak asuh. Anak belajar dengan meniru hal yang dilihat dan didengar dari orang lain. Bandura (1986) menjelaskan tentang belajar mengobservasi yang terdiri dari empat tahap yaitu: (1) perhatian pada perkataan dan perilaku contoh; (2) ingatan pada perkataan dan perilaku contoh; (3) reproduksi motorik yaitu melakukan seperti contoh; (4) dan penguatan berupa hadiah atau hukuman yang diterima contoh sehingga perilaku dari contoh akan ditiru atau tidak (King, 2011).

Anak banyak sekali bertanya tentang Allah SWT, pahala, surga, neraka, tujuan dan tata cara ibadah. Di usia 5-6 tahun perkembangan kognitif mereka masih pre operasional. Anak mengkreasikan konsep Tuhan dengan objek yang telah dia kenali (Kaiser \& Riegel, 2020). Hal ini menjadikan orang tua kadang merasa kesulitan dan kebingungan menjawab dan menjelaskan. Jawaban dari orang tua mempengaruhi imajinasi anak tentang Tuhan (Helandkurzak, 2019). Sebagaimana diteladankan oleh Nabi Ibrahim AS dalam bercakap dengan putranya, Nabi Ismail AS, sebelum menjelaskan tentang agama hendaknya orang tua 
membangun kebersamaan dan rasa percaya terlebih dahulu agar tercipta komunikasi yang baik dengan anak. Saat berbicara dengan anak, orang tua memahami tahap perkembangan kognitif dan moral anak. Ketika anak tidak bersedia melakukan ibadah orang tua tidak perlu mengancam karena anak belum tahap bisa membedakan yang baik dan buruk. Dengan cara demikian orang tua berhasil menanamkan religiusitas ibadah salat dan puasa kepada anak. Anak dengan senang hati beribadah salat dan puasa.

\section{SIMPULAN}

Pengenalan iman dan ibadah bagi anak sangat memerlukan keterlibatan orang tua dalam proses bimbingannya. Bentuk keterlibatan orang tua yaitu melakukan percakapan tentang ibadah dengan anak. Model percakapan Nabi Ibrahim AS dengan Nabi Ismail AS tentang ibadah kurban yang merupakan wujud kepatuhan dari hamba kepada Allah SWT secara efektif dapat digunakan dalam rangka pengenalan iman dan ibadah bagi anak usia dini dengan melalui membina kebersamaan dan kepercayaan dengan anak dan bentuk komunikasi yang baik sebagaimana yang ditunjukkan oleh hasil penelitian ini. Temuan bentuk percakapan orang tua - anak di antaraya adalah Bapak: "Tapi kamu akan puasa?" Anak: "Ya puasa". Bapak: "Kuat?" Anak: "Ya, kalau tidak kuat aku bobok." Bapak: "Alhamdulillah, anak kuat puasa setengah hari. Kalau tidak kuat, minum tidak apa-apa."

\section{UCAPAN TERIMA KASIH}

Peneliti mengucapkan terima kasih kepada Pimpinan Program Studi Magister Psikologi Sains Sekolah Pascasarjana Universitas Muhammadiyah Surakarta atas kesempatan melaksanakan penelitian ini, serta kepada tiga bapak dan ibu yang telah bersedia menjadi informan dalam penelitian ini.

\section{DAFTAR PUSTAKA}

Al Qur'an Dan Terjemahannya. (1995). Departemen Agama Republik Indonesia.

Asy'ari, H., \& M., D. B. I. (2019). Peran Orang Tuan Dalam Implementasi Program Keagamaan Anak Usia Dini Pada Kb-Tk An-Nisa Krian Sidoarjo. Martabat: Jurnal Perempuan Dan Anak, 3(1), 87-102. https:// doi.org/10.21274/martabat.2019.3.1.103-120

Bano, M., \& Ferra, E. (2018). Family Versus School Effect On Individual Religiosity : Evidence From Pakistan. International Journal of Educational Development, 59(December 2016), 35-42. https://doi.org/10.1016/j.ijedudev.2017.10.015

Boyatzis, C. J. (2013). The Nature and Functions of Religion and Spirituality in Children. APA Handbook of Psychology, Religion, and Spirituality, 1, 497-512. https://doi.org/10.1037/14045-027

Boyatzis, C. J., \& Janick, D. L. (2003). Parent-Child Communication About Religion: Survey And Diary Data On Unilateral Transmission And Bi-Directional Reciprocity Styles. Review of Religious Research, 44(3), 252-270. https:// doi.org/10.2307/3512386

Brambilla, M., Assor, A., Manzi, C., Regalia, C., \& Brambilla, M. (2015). Autonomous Versus Controlled Religiosity: Family and Group Antecedents Autonomous Versus Controlled Religiosity: Family and Group Antecedents. The International Journal for the Psychology of Religion, 25, 193-210. https:// doi.org/10.1080/10508619.2014.888902

Bunnell, P. W., Yocum, R., Koyzis, A., \& Strohmyer, K. (2018). Parental Involvement in Elementary Children ' s Religious Education: A Phenomenological Inquiry. Journal of Research on Christian Education, 27(1), 1-19. https:// doi.org/10.1080/10656219.2018.1442269

Callanan, M. A., \& Oakes, L. M. (1992). Preschoolers ' Questions and Parents ' Explanations : Causal Thinking in Everyday Activity. Cognitive Development, 213-233. https://doi.org/10.1016/0885-2014(92)90012-G

Cassibba, R., Granqvist, P., \& Costantini, A. (2013). Mothers ' Attachment Security Predicts Their Children ' S Sense Of God ' S Closeness. Attachment \& Human Development, 15(1), 37-41. https://doi.org/10.1080/14616734.2013.743253

Creswell, J. W. (2012). Educational Research (4th ed.). Pearson. 
Dalton, H., Dollahite, D. C., \& Marks, L. D. (2018). Transcendence Matters : Do the Ways Family Members Experience God Meaningfully Relate to Family Life ? Review of Religious Research, 60(1), 23-47. https:// doi.org/10.1007/s13644-017-0317-2

Fasoli, A. D., \& Lozano, G. (2019). Parent-Child Conversations And The Socialization Of Moral Autonomy In A Progressive Protestant Church Community. Journal of Moral Education, 1-20. https:// doi.org/10.1080/03057240.2019.1667755

Gustanti, L. (2017). Komunikasi Interpersonal Orang Tua Dan Anak Dalam Menanamkan Nilai Ibadah Shalat Di Kelurahan Labuhan Ratu Raya Kecamatan Labuhan Ratu Bandar Lampung. http://repository.radenintan.ac.id/855/1/SKRIPSI_LESTI_GUSTANTI.pdf diakses tanggal 15 Agustus 2021.

Handayani, M. (2016). Peran Komunikasi Antarpribadi Dalam Keluarga Untuk Menumbuhkan Karakter Anak Usia Dini. Jurnal Ilmiah VISI PPTK PAUDNI, 11(1), 57-64. https://doi.org/10.21009/JIV.1101.8

Heland-kurzak, K. A. (2019). Children ' S Creation Of An Image Of God And Religiosity - A Pedagogical Perspective Pedagogical Perspective. International Journal of Children's Spirituality, 1-13. https://doi.org/10.1080/1364436X.2019.1672625

Huliyah, M. (2016). Hakikat Pendidikan Anak Usia Dini. As Sibyan, 1(1), 60-71.

Husen, H. (2017). Metode Ta'dib dan Komunikasi Islami Menurut Perspektif Al-Qur'an dan Hadist dalam Pembangunan Karakter Anak Usia Dini Ta'dib. Golden Age, 1(2), 43-50. https://doi.org/10.29313/ga.v1i2.3385

Irhamna. (2016). Analisis Tentang Kendala-Kendala Yang Dihadapi Orang Tua Dalam Pembinaan Akhlak Dan Kedisiplinan Belajar Siswa Madrasah Darussalam Kota Bengkulu. Al Bahtsu, 1, 5765.

Kaiser, K., \& Riegel, U. (2020). Differences In Children ' S Concepts Of God . A Replication Study Based On Creative Tasks With Different Materials. International Journal of Children's Spirituality, 110. https:// doi.org/10.1080/1364436X.2020.1826411

King, L. A. (2011). The Science of Psychology (2nd ed.). McGraw-Hill.

King, P. E., \& Boyatzis, C. J. (2015). Religious and Spiritual Development. Handbook OfChild Psychology and Developmental Science, 7th Edition, Edited by Richard M. Lerner, John Wiley \& Sons, Inc. 1, 1-40. https:/ / doi.org/10.1002/9781118963418.childpsy323

Leersum-bekebrede, L. Van, Sonnenberg, R., Kock, J. De, \& BArnard, M. (2019). Setting The Stage For Children ' S Participation In Worship Practices. International Journal of Children's Spirituality, 24(2), 166-182. https://doi.org/10.1080/1364436X.2019.1619533

Lestari, P. (2018). Strategi Komunikasi Dalam Pembinaan Ibadah Pada Yayasan Yatim Piatu Kemala Puji Bandar Lampung. http://repository.radenintan.ac.id/4641/1/puji\%20lestari.pdf diakses tanggal 15 Agustus 2021.

Luria, E., \& Katz, Y. J. (2019). Parent - Child Transmission Of Religious And Secular Values In Israel. Journal of Beliefs \& Values, 1-16. https://doi.org/10.1080/13617672.2019.1688472

Pulungan, E. N. (2018). Peranan Orang Tua dalam Mengajarkan Pendidikan Shalat Pada Anak Sejak Usia Dini. Raudhah, 06(01), 1-26.

Qoyyimah, U. (2016). Inculcating Character Education Through EFL Teaching In Indonesian State Schools Indonesian State Schools. Pedagogies: An International Journal ISSN:, 1-18. https://doi.org/10.1080/1554480X.2016.1165618

Rizky, R. N., \& Moulita. (2017). Penanaman Nilai-Nilai Islam Melalui Komunikasi Interpersonal Orang Tua. Interaksi, 1(2), 206-219.

Sit, M. (2016). Mengembangkan Sikap Cinta Allah Dan Rasul Melalui Metode Kisah Pada Anak Usia Dini. Raudhah, 4(1), 22-32. https://doi.org/10.31004/obsesi.v1i1.29

Stearns, M., \& Mckinney, C. (2018). The Relationship Between Parent and Child Religiosity: Moderation by Perceived Parental Antisocial Problems. The International Journal for the Psychology of Religion, 1-41. https://doi.org/10.1080/10508619.2018.1493663

Subqi, I. (2016). Pola Komunikasi Keagamaan Dalam Membentuk Kepribadian Anak. Inject, 1(2), $165-$ 180. https://doi.org/10.18326/inject.v1i2.648

Sulaiman, A., Jamsari, E. A., \& Noh, N. C. (2014). Islamic Environment in Child Development According to the Views of Imam al-Ghazali. Mediterranean Journal of Social Sciences, 5(29), 33-39. https://doi.org/10.5901/mjss.2014.v5n29p33

Syamsudin, A. (2008). Tuhan Dan Alam Pikiran Anak. Humanika, 8(1). https://doi.org/10.21831/hum.v8i1.21004 
Trimuliana, I., \& Dhieni, Nurbiana, H. (2019). Perilaku Religius Anak Usia 5-6 Tahun pada PAUD Model Karakter. Obsesi, 3(2), 570-577. https://doi.org/10.31004/obsesi.v3i2.251

Trovão, S. S. (2017). Parental Transmission of Religion and Citizenship among Migrant Muslim Families in Mozambique , Portugal , United Kingdom and Angola. Journal of Muslim Minority Affairs ISSN:, 37(2), 129-146. https:// doi.org/10.1080/13602004.2017.1345102

Umroh, I. L. (2019). Peran Orang Tua Dalam Mendidik Anak Sejak Dini Secara Islami Di Era Milenial. Ta'lim, 2(2), 208-225.

Yust, K. (2017). Cultivating Christians: North American Family Cultures And Religious Identity Formation. International Journal of Children's Spirituality, 22(3), 260-273. https://doi.org/10.1080/1364436X.2017.1363721

Zainab, S. (2017). Komunikasi Orang Tua-Anak Dalam Al-Quran. Nalar, 1(1), 48-58. https://doi.org/10.23971/njppi.v1i1.901 